\title{
The contribution of vacuolated foetal-type enterocytes in the process of maturation of the small intestine in piglets. Invited review
}

\author{
T. Skrzypek ${ }^{1,6}$, S. Szymańczyk ${ }^{2}$, K. Ferenc ${ }^{3}$, W. Kazimierczak ${ }^{4}$, K. Szczepaniak ${ }^{5}$ and R. Zabielski ${ }^{3}$ \\ John Paul II Catholic University of Lublin, Center for Interdisciplinary Research, \\ Department of Biotechnology and Environmental Sciences, 20-708 Lublin, Poland \\ 1 Laboratory of Confocal and Electron Microscopy \\ ${ }^{4}$ Laboratory of Biocontrol, Production and Application of Entomopathogenic Nematodes \\ University of Life Sciences in Lublin, Faculty of Veterinary Medicine, 20-950 Lublin, Poland \\ ${ }^{2}$ Department of Animal Physiology \\ ${ }^{5}$ Institute of Biological Bases of Animal Diseases, Sub-Department of Parasitology and Invasive Diseases \\ ${ }^{3}$ Warsaw University of Life Sciences - SGGW, Faculty of Veterinary Medicine, \\ Department of Large Animal Diseases with Clinic, 02-776 Warsaw, Poland
}

KEY WORDS: foetal-type enterocytes, colostrum uptake, postnatal development, mucosa rebuilding, large vacuoles, giant vacuoles

Received: $\quad 6$ June 2018

Revised: 18 July 2018

Accepted: 27 August 2018

${ }^{6}$ Corresponding author: e-mail: tskrzypek@kul.pl

\begin{abstract}
In neonates the vacuolated foetal-type enterocytes (VFE) play a key role in the transport of intact colostral and milk proteins from the lumen of the small intestine into the circulation and/or in the intracellular digestion of intestinal nutrients. The absorption of intact colostral macromolecules (including immunoglobulins, hormones and bioactive peptides) is important in the development of the immune and digestive systems of newborn piglets. The digestion of the intestinal content inside the VFE supports the luminal digestion of nutrients. The presence of apical canalicular system, which produces both the transport and the digestive vacuoles, is a key feature of VFE. The VFEs are gradually replaced by adult-type enterocytes. VFEs disappear gradually from the proximal part of the small intestine to the ileum. VFEs containing large (also referred to as giant) transport vacuoles disappear within the first 2-3 days after birth. VFEs containing digestive vacuoles are present for up to week 3 of life. In contrast, VFEs of intrauterine growth retarded piglets show abnormalities in their development of the apical area. The loss of VFEs is a good marker of the small intestine epithelium maturation.
\end{abstract}

\section{Introduction}

The primary function of the epithelium of the small intestine is creating a barrier to secure selective transfer of desired high molecular weight substances from the lumen of the intestine to the venous and lymphatic systems of the intestine by transcellular and paracellular routes (Hollander, 1992; Travis and Menzies, 1992). The functions of the intestinal barrier, such as impenetrability and selectivity, depend on the degree of development of the intestinal mucosa. The selectivity of the transfer of nutrients is provided by proper receptors (Guyton and Hall, 1996; Biernat, 2002; Pasternak et al, 2015, 2016).

Dysfunction of the intestinal barrier is linked with a disturbance of its function and susceptibility 
to infection with intestinal pathogens, leading to diseases such as necrotizing enterocolitis (NEC), obesity, celiac disease and food allergies (König et al., 2016). The stability of the physical barrier created by the epithelium is secured by tight junctions (McCarter et al., 2010).

Tight junctions are transmembrane protein complexes that join adjacent epithelial cells of the small intestine in the vicinity of their apical periapical lateral zone. The core complex of the junctions consists of transmembrane proteins (occludin and claudin) and connecting adhesion molecules. The expression of claudin changes throughout the life of the cells. Occludins and claudins interact with the proteins of zonula occludens ( $\mathrm{ZO}$ ), which form connections with the actin cytoskeleton, affecting among other things the control of the cell cycle, the polarity of the cells and the permeability of the membranes. Tight junctions play a key role in the paracellular permeability by regulating the flow of ions, small particles and water-soluble substances between the epithelial cells (Dörfel and Huber, 2012). They also regulate the cellular polarity, by preventing the diffusion of receptors from the cellular membranes above the tight junctions to the basolateral membrane, which may influence the cells' reactions to directional stimuli, transport functions, as well as their proliferation (König et al., 2016). The location of tight junction proteins is different in neonates and in adult animals. Pasternak et al. (2015) reported that Claudin-4 was mainly localized in the apical part of jejunal epithelial cells for the first 2 days of life; next, Claudin-4 was redistributed to the lateral surface between adjacent enterocytes. In adult animals, the intestinal barrier created by the epithelium is highly selective. In neonates, it is periodically permeable for macromolecules without preselection of the absorbed substances, allowing the maternal antibodies and bioactive compounds of colostrum and milk to pass unchanged through the intestinal epithelium (Jensen et al., 2001; Baintner, 2002, 2007; Salmon, 2012).

The purpose of this article is to critically summarize the hitherto knowledge of the intestinal epithelium of newborn piglets with particular regard to the dynamics of morphological, molecular and functional changes in successively emerging enterocyte populations and their immediate environment.

\section{Epithelium of the small intestine in the postnatal period - types of enterocytes}

Already in 1971 Clarke and Hardy described differences between the epithelium of newborn and older piglets. In newborn animals there exists a population of foetal-type enterocytes (also referred to as vacuolated foetal enterocytes, VFE) which disappears as the intestine matures (Moon, 1972; Biernat, 2002; Baintner, 2002, 2007; Skrzypek et al., 2007a, 2018). This unique population of cells has the ability to absorb macromolecules and non-selectively transport and transfer the macromolecules to the blood with preservation of their biological activity. VFEs can be recognized by the presence of large vacuoles (also referred to as giant vacuoles) (Figure 1). In addition to transporting substances, VFEs also demonstrate the ability to digest them in the cellular lumen inside giant vacuoles. Baintner $(1994,2007)$ distinguished two types of vacuoles present in the foetal-type enterocytes: giant transport vacuoles and giant digestive vacuoles. The transport vacuoles are able to move inside the lumen of the enterocyte and appear just after the first feeding with colostrum. The vacuoles that are formed in the supranuclear area of the enterocyte accumulate in their lumen substances, which are taken up from the intestinal lumen by the process of endocytosis. They then move to the basal part of the cell, where they release their content via exocytosis into the intercellular space, from where it reaches the lymphatic and blood vessels. This is an important way of transferring the macromolecules of colostrum, known as opening of intestinal barrier and observed only within the first 2 days of the postnatal life in piglets. In contrast to the transport vacuoles, the digestive vacuoles are not able to move. In suckling piglets, they are located above the nucleus and often occupy $2 / 3$ of the volume of the enterocyte (Figure 2). In their lumen are stored nutrients collected from colostrum and milk, which are undergoing decomposition due to enzymes released by lysosomal vesicles connecting with the vacuoles. From there, the final products of the digestion, i.e. amino acids and simple sugars, reach the blood. Foetal enterocytes have been observed in the distal section of jejunum on the day 110 of the foetal life of piglets (Dekaney et al., 1997). The main digestive glands of the neonatal gastrointestinal tract - the salivary gland, the stomach, and the pancreas - are characterized. by a low capacity to secrete enzymes (Biernat et al., 1999). The proteolytic and lipolytic activities of the brush border enzymes of enterocytes are also low (Zabielski, 1998, 2007). Due to the immaturity of the digestive system, the role of these vacuoles is to actively participate in the digestion of the nutrients of colostrum and milk (Baintner, 1986). 


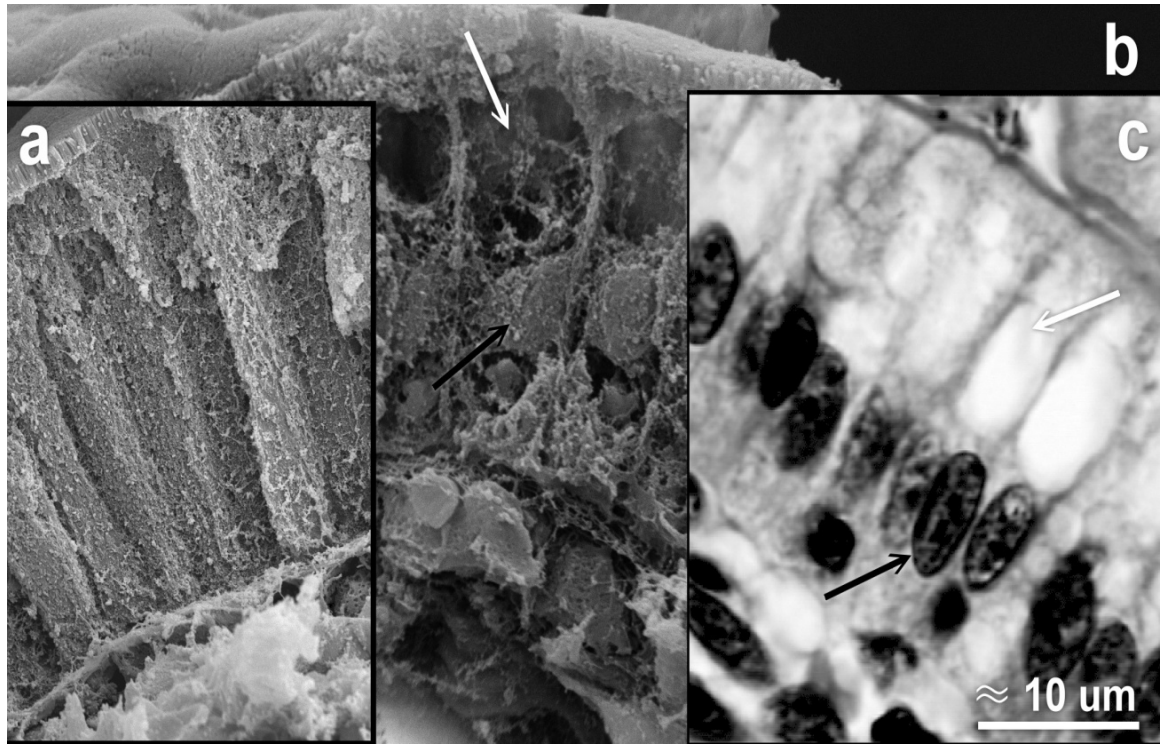

Figure 1. Scanning electron microscopy micrographs of a section of pig's mature enterocytes at day 21 after birth in the mid jejunum (a), vacuolated enterocytes at day 3 of life in ileum (b) and vacuolated enterocytes at day 3 of life in ileum (optical microscope, haematoxylin and eosin stain (c)

Note: empty spaces left after the content of the vacuoles were washed out during preparation ( $b$, white arrows) and nucleus (b, black arrows).

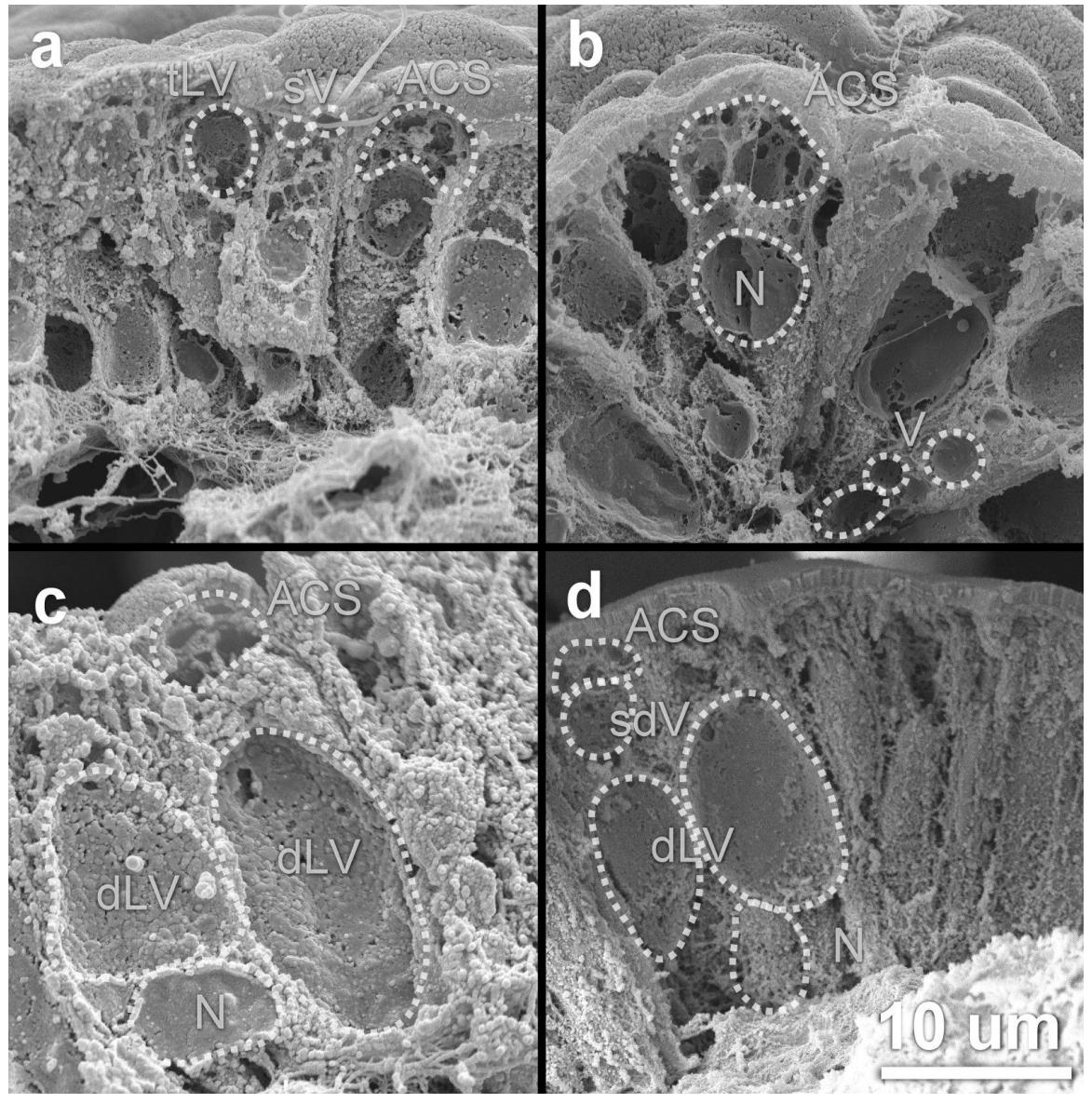

Figure 2. Scanning electron microscopy micrographs of vacuolated enterocytes with the spaces left after the content of the vacuoles washed out during preparation: transport vacuoles $(a, b)$ and vacuolated enterocytes with digestion vacuoles $(c, d)$

Note: localization of apical canalicular system (ACS) under apical membrane, small vacuoles (sV), transport vacuoles (tLV), small vacuoles near the basal part $(\mathrm{V})$, small digestive vacuoles (sdV), large digestive vacuoles (dLV) and nucleus (N). 


\section{Why and how foetal-type enterocytes can absorb macromolecules?}

To develop normally, pig neonates must receive from colostrum proper quantities of macromolecules: immunoglobulins, hormones, growth factors, biologically active peptides and nutrients, and especially proteins. A characteristic feature of the neonatal small intestine, conditioned on the presence of the giant vacuoles arising in the foetal-type enterocytes, is the mentioned ability to non-selectively absorb high molecular weight substances for only a short period after birth (Sangild, 2003; Baintner, 2007; Salmon et al., 2012). VFEs enable the absorption and transport of proteins and colostrum and milk macromolecules from the intestinal lumen into the bloodstream with preservation of their biological activity (Burton and Smith, 1977; Zabielski, 1998). An interim absorption through an open intestinal barrier of ingredients derived from colostrum is observed in nearly all mammals during the postnatal development. Although this phenomenon in humans is not a condition of survival, neonatal pigs, sheep and cows are born with physiologically low protein and antibody levels in the serum (Lecce and Morgan, 1962; Nechvatalova et al., 2011). This is due to a specific structure of the placenta, which does not allow for the transfer of immunoglobulins during the foetal period. In these animals, the presence of vacuolated enterocytes of the transport type allows for the absorption of colostral immunoglobulins during the early postnatal period (Kelly et al., 1992; Nechvatalova et al., 2011; Bandrick et al., 2014). The immunoglobulin absorption by the VFEs, based on nonselective pinocytosis, during this period is essential for the immunity of the entire body (Brandtzaeg and Krajci, 1995; Salmon et al., 2009). The mammalian $\mathrm{Fc}$ receptors $(\mathrm{FcRn}$, neonatal $\mathrm{FcR}$ ) responsible for the transmission of antibodies reported in different species (Baintner, 1986, 2007; Simister, 2003; Kacskovics, 2004) seem an alternative mechanism of antigen uptake. Anderson et al. (2006) reported that the FcR receptors observed during the neonatal period are multifunctional proteins expressed at all ages in different tissues.

In piglets, among the substances absorbed from the intestinal lumen via the process of non-selective endocytosis, are also regulatory peptides, growth factors, hormones and exogenous markers (Weström et al., 1984; Baintner, 1986; Zabielski, 1998; Teichberg et al., 1992). The ability of absorbing exogenous markers: mannitol, synthetic oligopeptides, bovine albumin and ovalbumin, FITC-dextran 4
(FD4) and horseradish peroxidase (HRP) by VFEs is utilized in investigations of the processes of absorption and transport of high molecular weight substances in mammalian intestines (Ekström et al., 1988; Denno et al., 2014). In rats, the small intestine retains the ability to absorb high molecular weight substances also due to the presence of a population of foetal enterocytes. Yet, the viability of rat neonates is not dependent on the gathering of colostral immunoglobulins as it is in the case of piglets (Baintner, 1986; Weaver and Walker, 1989).

The main factor that accelerates the closing of the intestinal barrier is the intake of food (colostrum), and its absence delaying the closing (Lecce and Morgan, 1962; Michanek et al., 1989; Biernat, 2002). In piglets, the feeding with colostrum, even of a non-cognate species, leads to the closing of the intestinal barrier (Lecce and Morgan, 1962). It is not only the type of the consumed food, but also the way of its administration that may have an impact on the development of the small intestine in neonates (Widdowson et al., 1976). In puppies, bottlefeeding inhibited the development of the intestine without influencing the weight gain (Heird et al., 1984; Yamashiro et al., 1989).

The transport of macromolecules through the epithelium happens by two routes: the paracellular route and the transcellular route (based on the mechanisms of pinocytosis and endocytosis). Some of the mechanisms pertaining to the process of absorption of macromolecules by the foetal-type enterocytes, such as the capture of maternal antibodies with the participation of the $\mathrm{FcR}$ receptor, are already quite well known (Salmon et al., 2009). Other, such as the paracellular transport (Svendsen et al., 1986) or the endocytosis through the canaliculi and cisterns at the uppermost part of the foetal enterocyte apical canalicular system (ACS) (Baintner, 2002), require further research. In the case of the paracellular transport, the tight junction proteins play a very important role (Anderson and Van Itallie, 1995). Pasternak et al. (2015) demonstrated in their research on piglets that the location of Claudin-4, a protein that is a component of tight junctions, is different in neonates and in adult animals. Claudins form tight junctions along with occludins and more than twenty other proteins. Tight junctions divide the membrane of the enterocytes into apical and baso-lateral areas and their constituent proteins are involved in the transport of substances. Claudin- 4 was present in the apical area of jejunal enterocytes in the first 2 days of life. After this period, it was also shown to be present on the lateral side of the enterocytes. 
The localization of the proteins participating in forming connections between the lateral cell membranes of enterocytes at their apical surface shortly after birth is essential for the development of tight junctions; they facilitate the transport of particles between neighbouring enterocytes and then seal the epithelium when the enterocytes are being replaced via apoptosis while the intestinal epithelium is undergoing its intense reconstruction.

The second route by which macromolecules can overcome the intestinal barrier is through pinocytosis/endocytosis at the apical area of the enterocyte (Fujita et al., 2007; Danielsen and Hansen, 2016). In the near apical part of the foetal-type enterocytes, ACS structures are being successively filled during the uptake of nutrients. The ACS system arises as a result of invagination of the apical membrane of the enterocyte (the mechanism of pinocytosis/endocytosis) into the cell (Baintner, 1986; Fujita et al., 1990). The invaginations form canaliculi, which are filled with the ingredients, are absorbed from the intestinal lumen. After closing, they create numerous small vacuoles, which can then connect into larger structures, eventually forming giant vacuoles (Moretti et al., 2013). The presence of this unique complex of canaliculi and vesicles facilitates the formation of giant vacuoles (Baintner, 1986; Weaver and Walker, 1989) (Figure 2). The size of the vacuoles is variable. The more intense is the absorption of macromolecules, the larger are the vacuoles. An exception to this are foetal enterocytes in piglets with intrauterine growth retardation (IUGR) syndrome in which the fusion of smaller vesicles into giant vacuoles was halted (Mickiewicz et al., 2012; Ferenc et al., 2017; Figure 3).

Endotubin (ES, also called Apical Endosomal Glycoprotein - AEGP, MAMDC4, and Apical Early Endosomal Glycoprotein - AEEGP) is a protein, which was shown to be present in the epithelial enterocytes of the small intestine in newborns. It seems to be of crucial importance in the transport of colostral macromolecules through the cell membrane of enterocytes. It is responsible for intermembrane transport of specific ingredients of colostrum in a way similar to the transport of immunoglobulins by $\mathrm{Fc}$ fragment of $\mathrm{IgG}$ receptor and transporter (FCGRT) (Pasternak et al., 2015, 2016). This protein was first identified by Wilson et al. (1987) in the mucosa of the rat ileum. The presence of this protein was demonstrated in the membranes of endosomal vesicles and in ACS (Wilson et al., 1987). MAMDC4 regulates the localization of the proteins comprising the tight junctions: Claudin 1 and occludin.

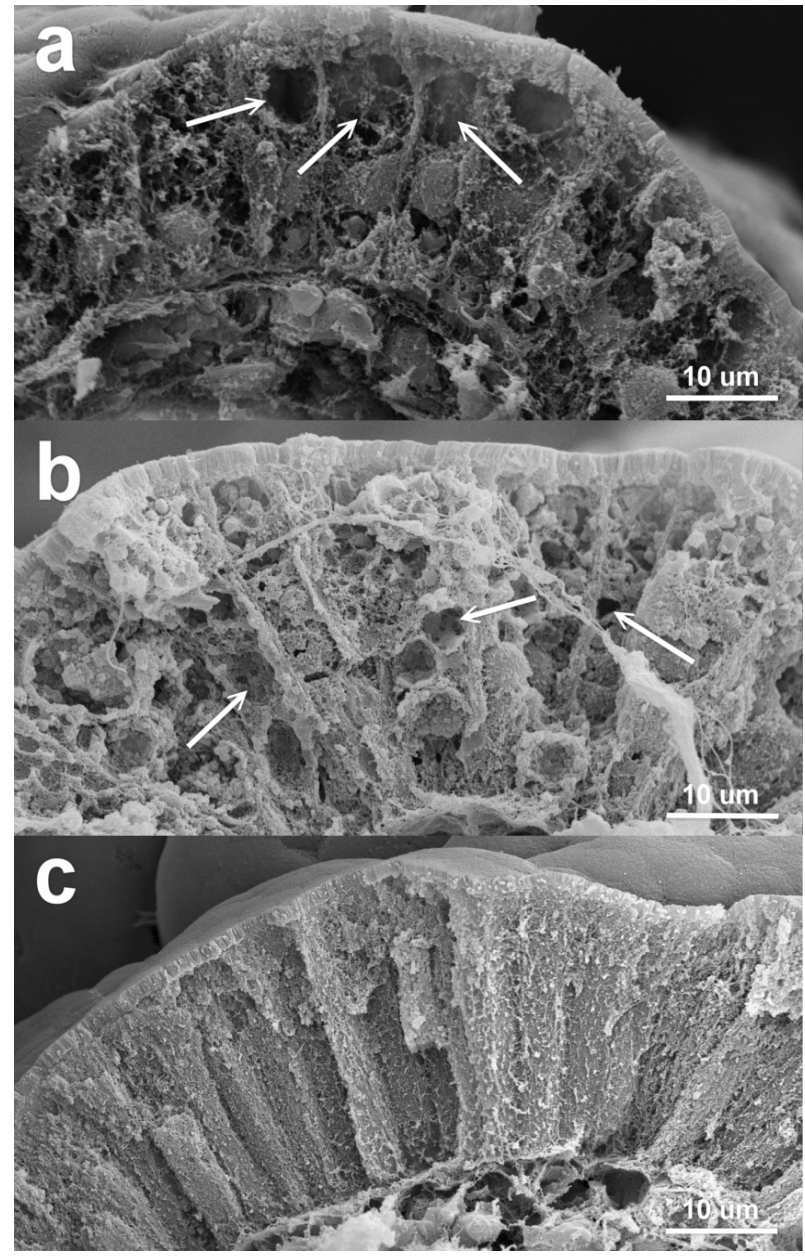

Figure 3. Scanning electron microscopy micrographs of vacuolated foetal enterocytes from the ileum of pigs at day 3 after birth (a), enterocytes from distal jejunum at day 7 of life from piglets with intrauterine growth retardation syndrome (b) and mature enterocytes from mid jejunum at day 21 of life (c)

Note: difference between 'normal' vacuolated foetal enterocytes (VFE) and intrauterine growth retardated (IUGR) piglets: large single vacuoles were present in the VFE enterocytes (a, arrows); no single large-size vacuoles were present in the IUGR enterocytes, only small ones (b, arrows).

In neonates the transcription of MAMDC4 was increasing in jejunum and ileum, but was later decreasing as the intestine development progressed. The expression of the MAMDC4 protein ceased on day 10 and 15 of life in the jejunum and ileum, respectively (Pasternak et al., 2016).

The vacuoles of the digestive type join lysosomes, which may lead to enzymatic breakdown of the content of the vacuoles (Baintner, 1986; Fujita et al., 1990). In piglets with the IUGR syndrome it was observed that the small vacuoles do not show the tendency to merge and create giant vacuoles. This may result in a disorder of the intracellular digestion, as the number of lysosomes in cells is limited and, it can be possible that not all small and medium-sized 
vacuoles contents will be digested (Ferenc et al., 2017; Figure 3). The molecular basis of the observed dysfunction remains obscure, but it may be assumed that what has occurred was a consequence of thrifty phenotype development in the gut mucosa involving the integral membrane proteins that form the ACS or the intracellular proteins that facilitate the fusion of vesicles and smaller vacuoles into increasingly larger structures. Further studies of the expression of both the tight junction forming proteins and the proteins responsible for the development of the ACS and the endocytosis may help to clarify the phenomenon of the 'semipermeable' intestinal barrier and the poorly functioning VFE apparatus in IUGR pig neonates.

\section{Large size vacuoles are already present shortly before birth}

Large size (giant) vacuoles are observed in enterocytes covering the surface of jejunal villi of foetal sheep from the day 90 of foetal life (pregnancy lasts on average 155 days) (Sangild et al., 2002). This is related to the uptake of nutrients, biologically active factors and hormones insulinlike growth factor (IGF), epidermal growth factor (EGF), insulin, gastrin) from the amniotic fluid. These substances initiate and control the prenatal development of the digestive tract (Trahair and Sangild, 1997). A foetus swallows large amounts of liquids during its development in the uterus and the increase in the digestive system is inhibited if the uptake of fluid by the foetus is impaired or experimentally limited (Trahair, 1993). During foetal development, the amniotic fluid penetrates into the intestinal lumen, which stimulates its growth, the differentiation of the epithelial cells and the activity of the brush border enzymes. The impact of the amniotic fluid on the development of the intestinal mucosa has been demonstrated by (Sangild et al., 2002) in an experiment in which the oesophagus of foetal sheep was ligated, preventing them from swallowing the amniotic fluid. At the end of pregnancy, sheep foetuses swallow up to 11 of amniotic fluid per day. It was observed that foetuses deprived of the ability to swallow the amniotic fluid had changed structure of the mucous membrane involving reduction of the surface of the villi, which may adversely affect the uptake of nutrients and regulatory substances by the epithelium.

Whereas in the sheep the uptake of the amniotic fluid is linked to the presence of the giant vacuoles, which implies a non-selective uptake of substances by the epithelium (Sangild et al., 2002). In piglets it is different, which is likely due to species difference. Similarly as in the sheep, the porcine foetal small intestine develops from a simple tube of stratified epithelium into a tube containing villi and intervillus regions of simple columnar epithelium. During the development, components of the ACS were observed by day 110 of gestation; the tubular and vesicular components of the AEC were confined to the jejunum, whereas large lysosomal vacuoles were observed in the distal part of the jejunum. At day 110, the duodenal epithelium was similar to the postnatal epithelium (Dekaney et al., 1997). It is possible that the uptake of macromolecules from the amniotic fluid occurs most intensely in the final section of the jejunum, while in other sections of the intestine the enterocytes with their ACS remain at the stage of 'readiness'.

\section{Consequences of the thrifty phenotype - peculiarities in the structure and function of foetal-type enterocytes in intrauterine growth retarded piglets}

In piglets born with the IUGR syndrome, a number of anomalies was found concerning the maturation of the small intestine. A disordered scheme of the loss of foetal-type enterocytes was first demonstrated by Mickiewicz et al. (2012). They showed that on the day of birth, the small intestine of piglets with IUGR contained $60-67 \%$ VFEs, while in the control group (piglets of normal gestational weight) the VFE represented around $40 \%$ of the small intestine enterocytes. In the same study it was shown that the structure of the interior of enterocytes is foamy and it is difficult to isolate from it such structures as giant vacuoles (Figures 4C and 4D). However, the internal structure of the enterocytes was not further investigated to clarify this phenomenon. It was only the research of Ferenc et al. (2017) that showed that in the enterocytes of individuals with IUGR supranuclear spaces do not contain the typical giant vacuoles observed in normal body weight (NBW) piglets. On day 7 of life the supranuclear part of the enterocytes present in the distal section of the jejunum looked like a foamy structure. It is very likely that the observed foetal-type enterocytes were similar to the ones present in the jejunum on the day 110 of the foetal development that were previously described by Dekaney et al. (1997). A study of proteomic 

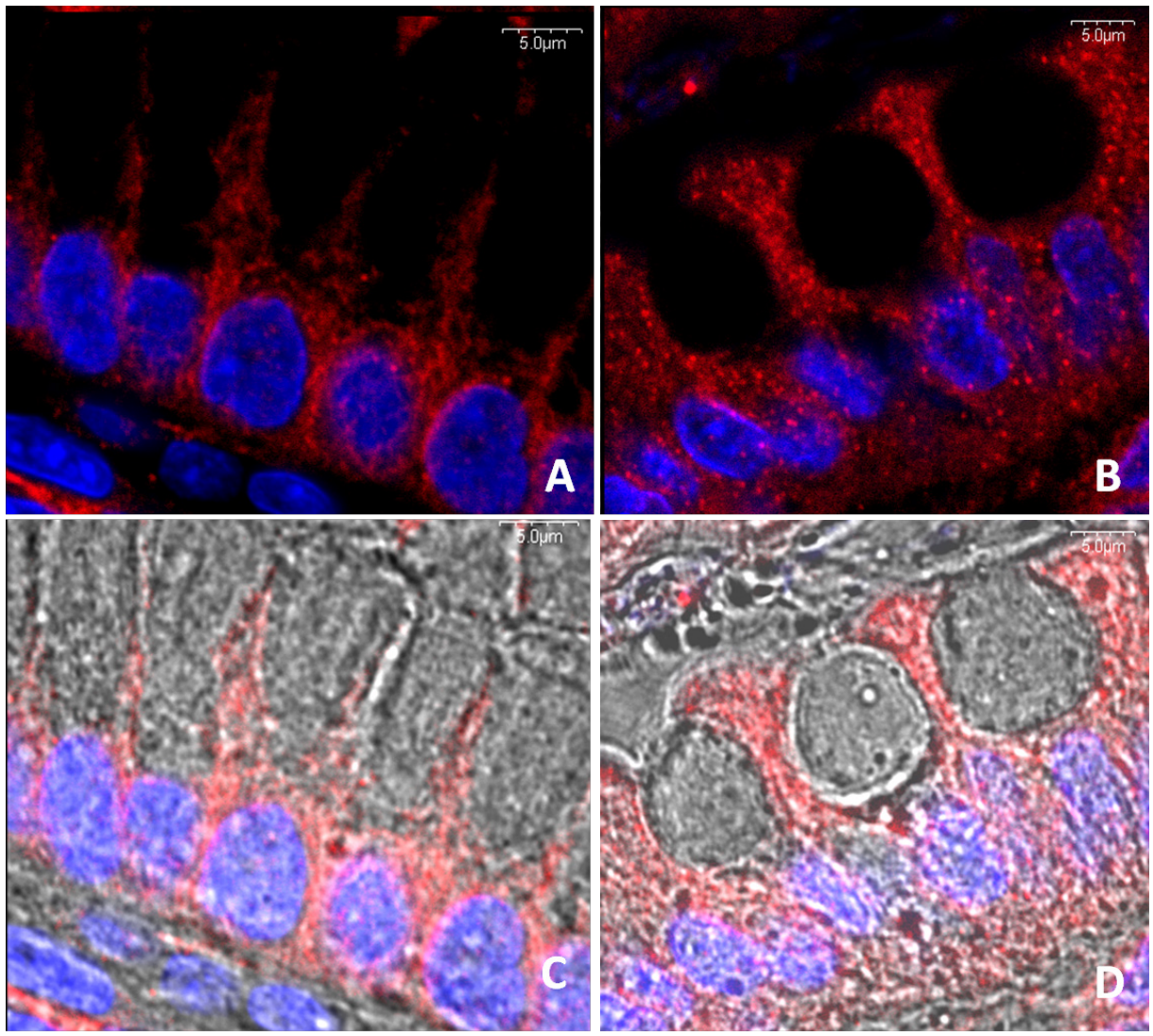

Figure 4. Foetal-type enterocytes in the duodenum of 7-day old intrauterine growth retardated (IUGR) piglets (A, C) as compared to piglets born with normal body weight (NBW) (B, D). In the IUGR (A) in comaprison to NBW (B) piglets decreased levels of tubulins involved in the process of building cytoskeleton are observed (tubulin - red fluorescence, cell nuclei - blue fluorescence). With additional transparent view, changes in the structure of large vacuoles are observed. In the IUGR piglets, the contours of the vacuoles are blurred (C) as compared to the NBW piglets (D).

profiles of the intestines of IUGR piglets at the middle (day 60) and late (day 110) stages of gestation showed changes in the levels of proteins relating to the structure of the cells, such as calponin-1, lamin $\mathrm{A} / \mathrm{C}$, transgelin, beta-actin, actin gamma 1 , ezrin, and septin 2 (Wang et al., 2014). With the use of scanning electron microscope (SEM) and confocal microscopy, significant differences in cellular ultrastructure were revealed in 7-day old IUGR piglets in comparison to NBW piglets. With the use of confocal microscope, it was demonstrated that the expression of lamin $\mathrm{A} / \mathrm{C}$ was reduced over the entire length of the mucous membrane. The reduced expression of this protein can be the cause or the consequence of the slowed-down mitotic divisions in the intestines of the IUGR piglets (Ferenc et al., 2017). Significant differences were also found in the architecture of the cytoskeleton not only in the foetal enterocytes but also in enterocytes of adults. These changes manifested themselves as reduced expression of tubulin and lack of the distinctive arrangement of tubules in the cytoplasm in comparison to the NBW piglets' enterocytes. The consequences of the changes in the cytoskeleton of the enterocytes may be increased susceptibility of the enterocytes to damage (e.g., in the course of inflammation), irregularities in their mitotic divisions, as well as the observed loss of the characteristic polarized cell layout (Figures 4 and 5).

In individuals with IUGR, the development of foetal enterocytes is more than a week delayed in relation to their NBW littermates, despite the uptake of colostrum and milk. Amdi et al. (2013) suggest that the growth disturbances in IUGR piglets may result from the lack of biologically active factors from colostrum. Since most IUGR piglets fall with stomachs partially or correctly filled with food, the reason for the piglets' growth disorders may be not so much a disorder of the uptake of colostrum as an impaired transfer of biologically active factors from the lumen of the intestine into the blood. The responsibility for it may lie with the observed disorder within the ACS and a disorder concerning the creation of giant vacuoles, both of the transport 

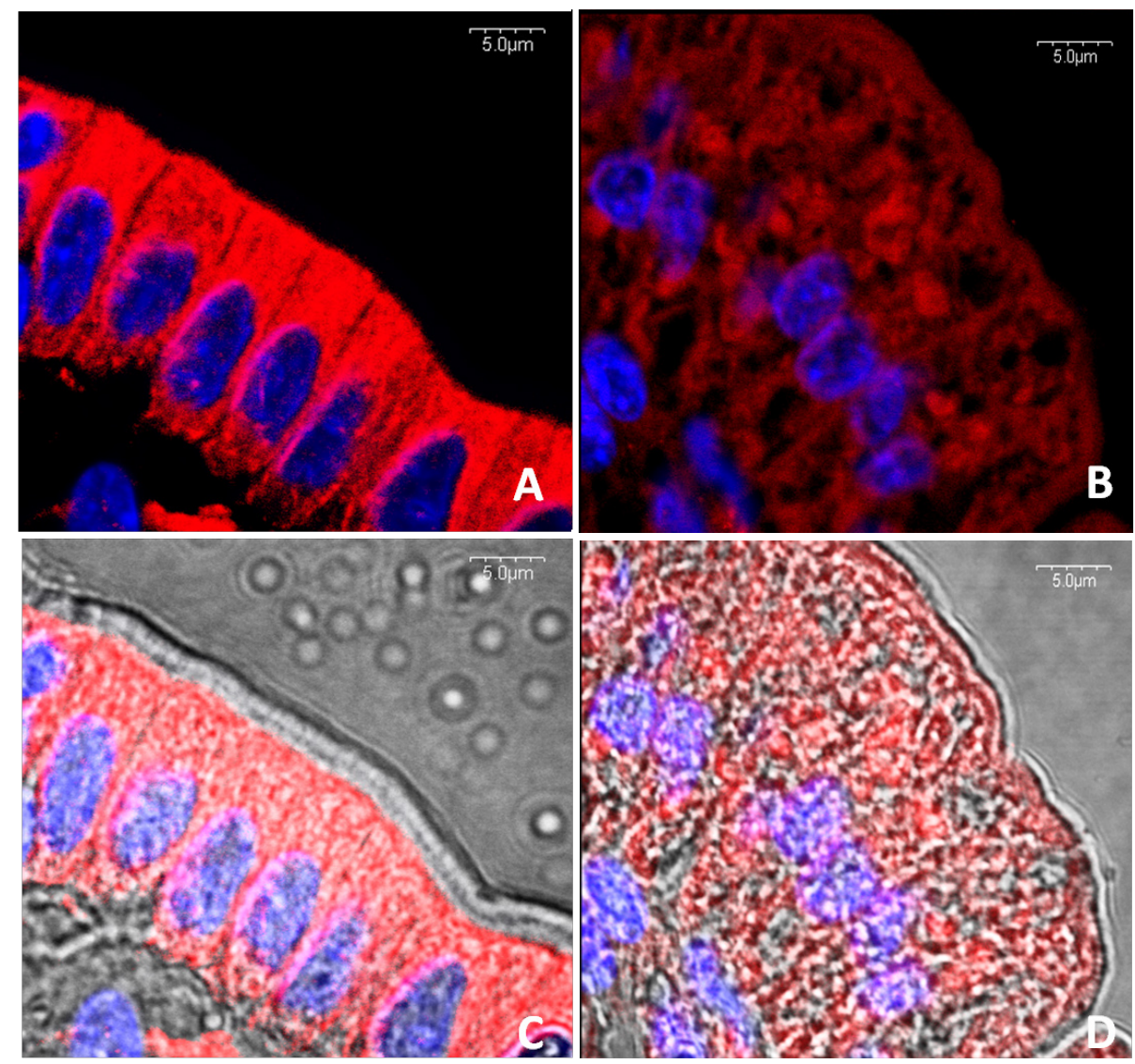

Figure 5. Adult type of enterocytes in the duodenum of 7-day old intrauterine growth retardated (IUGR) piglets (A, C) as compared to piglets born with normal body weight (NBW) (B, D). In the IUGR (A) in comparison to the NBW (B) piglets the characteristic tubules involved in the process of building a cytoskeleton are lacking (tubulin, red fluorescence). Moreover, the architecture of the IUGR's enterocytes lacks its characteristic polarization. The cell nuclei are in the central part of the cell (blue fluorescence). With additional transparent view, it was observed that the brush border space in the IUGR piglets (C) was thinner than in the NBW (D) ones.

and the digestive variety (Mickiewicz et al., 2012; Ferenc et al., 2017). On the other hand, Wang et al. (2016) showed that the intestinal permeability was twice as high in the IUGR piglets on the day of their birth. This study was performed with the use of FD4 and HRP at the proximal segment of the small intestine of newborn piglets. On day 3 of life, however, the intestinal permeability was 3 times higher for FD4 and 4 times higher for HRP in comparison to the control group (NBW). These results were consistent with the decreased expression of occludin. Nothing is known about the function of the newly described interstitial organ in the intestinal mucosa of individuals with the IUGR syndrome (Benias et al., 2018). The impairment of its structure and function cannot be ruled out, and thereby the inhibition of the transfer of nutrients in comparison to the NBW neonates by dysfunctional intercellular spaces both within the intestinal villi and in other parts of the mucous membrane (own unpublished observations).

\section{How do the changes in the enterocyte structure fit into an old concept of open gut barrier and its closing?}

The mechanism of open intestinal barrier is associated with the presence of foetal-type enterocytes capable of creating giant transport vacuoles (Zabielski, 1998). In adult animals, the intestinal barrier is a requisite for selective transfer of particles from the intestinal lumen, through the epithelium, and to the blood. In newly born piglets fed colostrum, the intestinal barrier is open for approximately $48 \mathrm{~h}$ after birth. In dogs, the closing of the intestinal barrier occurs earlier than in most other species and takes place after 16-24 h (Chastant-Maillard et al., 2012). In other species, such as rat, mouse and ferret, the intestinal closure does not occur until several weeks after birth (Baintner, 1986). The foetal enterocyte population with giant transport vacuoles that is required for the opening of the intestinal barrier in piglets is observed over the entire length of the 
small intestine, from the duodenum to the ileum, and represents approximately $2 \%$ of the enterocyte population (Biernat, 2002).

The process of the closing of the intestinal barrier in piglets, as well as in other newborn mammals, has not been completely elucidated. On the one hand, the closure of intestinal barrier in piglets is linked with the disappearance of the giant transport vacuoles and the replacement of the foetal enterocytes with the mature enterocytes, i.e. the ones devoid of giant vacuoles (Baintner, 1994). On the other hand, the closing of the intestinal barrier in piglets does not have to be directly related to the disappearance of all foetal-type enterocytes, but may be related to the age of the epithelial cells (Moon, 1972). Clarke and Hardy (1971) demonstrated the ability of vacuolated foetal digestive-type enterocytes present in the intestine in the week 3 of life to uptake macromolecules of polyvinylpyrrolidone (PVP). But the ability of enterocytes to uptake macromolecules from the lumen of the intestines is not the same as their release into the bloodstream. According to the above mentioned authors, already $5 \mathrm{~h}$ after birth the PVP is not transported from the epithelium into the bloodstream despite the presence of the foetal-type enterocytes. In neonatal humans, the time of closing of the intestinal barrier depends on the quantity of the taken-up antibodies and on the time of the start of the uptake of colostrum (Vukavić, 1984). Vukavić (1984) suggested that an early gut closure is caused either by some colostral factor(s) or by some other mechanism that prevents further macromolecular absorption. He reported that in neonates in which breast feeding started after $24 \mathrm{~h}$ of life, the serum immunoglobulin A (IgA) concentrations increased significantly, suggesting that if breast feeding is postponed, a spontaneous gut closure may also be postponed and may not take place within the first $30 \mathrm{~h}$ of life.

In addition to immunoglobulins, the colostrum contains a variety of factors that may accelerate the process of closing of the intestinal barrier (Tyler and Ramsey, 1993). It seems that the closing of the intestinal barrier depends on the uptake by the organism of the newborn of an appropriate quantity of biologically active factors and immunoglobulins present in the colostrum within a specified time window (Grognet and Duvaux-Ponter, 1998). It was shown that the closing of the intestinal barrier was extended in piglets that did not receive the appropriate amount of biologically active factors from the colostrum. In piglets receiving a milk replacer, the mitotic and apoptotic indices were significantly lower, and the proportion of vacuolated enterocytes was higher than in piglets that were fed colostrum, indicating a slowed down replacement of intestinal epithelial cells. The observed phenomenon may be disadvantageous for the newborn as it extends the period of open/insufficiently closed intestinal barrier, which facilitates the intrusion of pathogens or allergens into the organism (Biernat, 2002, Fujita et al., 2007).

Despite the closure of the intestinal barrier, high molecular weight substances may still be taken up into the digestive vacuoles of the so called foetal enterocytes of the digestive type located in a further segment of the jejunum and in the ileum for up to week 3-4 of postnatal life (Lecce, 1973; Lecce and Broughton, 1973). In the first 2 days after birth, macromolecules present in milk reach the bloodstream intact using foetal enterocytes equipped with transport vacuoles. Later, however, the macromolecules present in milk only enter the foetal enterocytes that are equipped with digestive vacuoles in which the intracellular digestion takes place, and only to a small extent reach the bloodstream in an unaltered state (Rådberg et al., 2001). This means that the components of colostrum and milk taken up in the process of endocytosis and locked in the vacuoles of enterocytes are treated as substrates of nourishment and digested with the participation of lysosomal enzymes. The digestion vacuoles assist therefore in the digestion of the ingredients of milk. It appears likely that due to the aforementioned limited activity of brush border enzymes (e.g., maltase and saccharase in newborns), an older evolutionary way of intracellular digestion is used at the initial stages of ontogenesis. Interesting in this context are the observations in individuals with IUGR syndrome of the defect in forming one giant transport vacuole in the lumen of the enterocyte (Ferenc et al., 2017). It is difficult to contest the deterioration of the performance of the processes of intracellular digestion in such cells, as was mentioned earlier, but to what extent are these cells able, for instance, to maintain the transport of macromolecules? It is also unknown how effective is the transfer of nutrients from these enterocytes to the intercellular space, and then to the lymph and blood of individuals with IUGR.

The aforementioned relationship between the opening of the intestinal barrier and the age of the cells takes on a whole new meaning in light of the research on the expression of the proteins present in the cell membranes of foetal enterocytes. The presence of tight junctions and the polarization of cells is a prerequisite for the proper functioning of the intestinal barrier. Endotubin, an integral membrane protein present in the endosomes of the apical part of the cells in the developing epithelium, 
participates in the creation of tight junctions and in determining the polarity of the epithelial cells. McCarter et al. (2010) showed that in cell cultures a distortion in the function of endotubin causes defects in the organization and functioning of tight junctions. They observed anomalies in the location of tight junction proteins, reduced selectivity of the mucous membrane and increased penetration of lanthanum via paracellular transport.

\section{Early postnatal maturation is put into effect by gradual disappearance of foetal-type enterocytes}

In piglets, the process of disappearance of the vacuolated enterocytes along the small intestine depends on the extent of the development of the intestinal mucosa and happens in the first three weeks of life (Clarke and Hardy, 1971; Moon, 1972; Sangild, 2001; Biernat 2002; Elbrønd and Weström, 2007 Skrzypek et al., 2007a, 2018). The disappearance of vacuoles takes place in the direction from the duodenum to the ileum. This means that the vacuoles persist the longest in the further sections of the jejunum and in the ileum. In the duodenum, vacuolated enterocytes were present only on the day of birth (Skrzypek et al., 2005). In the proximal section of the small intestine giant vacuoles were observed up to day 3 of life; they were present the longest in the distal section of the jejunum - up to days 7-14 of life, and in the ileum up to day 14, and often up to day 21 of life (Skrzypek et al., 2007a; Figure 2). Our own research, carried out using SEM and confocal microscope, made it possible to ascertain the existence of giant vacuoles in the small intestine of piglets during the postnatal period (Skrzypek et al., 2005, 2007a; Godlewski et al., 2005). The SEM techniques do not allow distinguishing the transport giant vacuoles from the digestive giant vacuoles. One may, however, assume with high probability that the vacuoles observed in the enterocyte population after day 2-3 represent already only the digestive vacuoles, as during this period the foetal enterocytes of the transport variety are already absent in the small intestine of piglets (Baintner, 1994). Observations made using SEM confirmed the presence of giant vacuoles in the enterocytes of further sections of the small intestine of piglets for up to week 2-3 of life (Skrzypek et al., 2007a). Clarke and Hardy (1971) observed enterocytes with giant vacuoles in the week 3 of life of the piglets. Discrepancy between studies results may be caused by many factors, such as differences in the diet of the sows in the final period of pregnancy and lactation, creep feeding of piglets, as well as the breed of animals (Zabielski, 2007). When the rates of development of the mucous membranes were compared between piglets of the Sus scrofa domestica and a pig and wild boar hybrid (Sus scrofa domestica/Sus scrofa), the pig/wild boar hybrid was found to exhibit a more dynamic development of its intestinal mucosa (Skrzypek, 2007b). Our unpublished data indicate that the VFEs disappear faster in the pig/wild boar hybrid than in the piglets of Pietrain breed. Observations indicate that the process of disappearance of the vacuoles may differ not only between breeds of pigs, but also between individuals within one litter, just like in the case of IUGR vs NBW.

The disappearing of the giant vacuoles in a population of foetal enterocytes is a reflection of the changes in the absorptive and digestive functions of the mucous membrane of the small intestine during the postnatal development. It was observed that in piglets, the closing of the intestinal barrier happened earlier than in rodents (Baintner, 1986). The disappearing of vacuolated enterocytes and the associated replacement of the population of foetal enterocytes with mature enterocytes is progressing along the small intestine for a particular time that is characteristic to each individual species of animals. The disappearing of vacuoles is a characteristic phenomenon and it may - in combination with other methods (e.g., measurement of the mitotic index) - be used as a morphological indicator of the pace of maturation of the mucous membrane of the small intestine (Rådberg et al, 2001; Biernat 2002).

\section{Effect of some biologically active substances in food on the removal of foetal-type enterocyte and thereby on gut development}

There are known substances, which can initiate, modulate, or/and accelerate the process of maturation of the intestinal mucosa and the replacement of foetal enterocytes with mature enterocytes (Rådberg et al., 2001). They include, inter alia, lectins, polyamines, butyric acid, glutamates and $\alpha$-ketoglutaric acid.

Lectins are antinutrient-type glycoproteins occurring in cultivated plants (beans, peas, and soybeans). Common bean lectin, when used at a proper dose, regulates the maturation of the intestinal (as well as pancreatic) functions (Bardocz et al., 1995, 1996; Rådberg et al., 2001). Repeated administrations of low doses of lectins to suckling piglets resulted in a reduction in the number of vacuolated enterocytes and the size of lysosomal vacuoles and 
influenced the activity profile of brush border enzymes. The activity of lactase increased, while the activity of maltase and saccharase decreased. The administration of bean lectin had also caused shortening of the intestinal villi, an increase in the depth of crypts, and the increase in the number of cells that were undergoing mitotic divisions within the crypts (Rådberg et al., 2001). The picture of changes due to the influence of lectins resembles the process of rebuilding of the intestine observed during weaning (Pluske et al., 1997).

Polyamines, which include spermidine and spermine, are complex compounds, occurring at high concentration in eukaryotic cells. They participate, among other things, in the processes of proliferation and differentiation of cells (Childs et al., 2003; Seiler and Raul, 2005). Gastric administration of spermine to piglets resulted in reduced thickness of the mucous membrane over the entire length of the small intestine, which resembles the changes observed after weaning. The reconstruction of the epithelium was confirmed by the loss of vacuolated enterocytes and by the change in the activity profile of the brush border enzymes, similar to the case of the use of bean lectin. Studies suggest that the mechanism of induction and maturing of the mucous membrane of the small intestine is linked with the participation of cytokines, interleukin (IL)-1 $\beta$ and IL-6, as well as tumour necrosis factor (TNF) $\alpha$ (Kaouas et al., 1997).

Butyric acid, glutamates and $\alpha$-ketoglutaric acid (derivatives of glutamine) are essential in the metabolism of animals. Glutamine and its derivatives are present in the body, in the extracellular fluid, where they constitute a significant percentage of all amino acids in the skeletal muscles (Neu et al., 1996). They are a source of energy for the metabolic processes in the digestive tract and a source of nitrogen for protein synthesis in the digestive tract, and this way affect the growth and activity of intestinal cells (Pierzynowski and Sjodin, 1998; Kotunia et al., 2004; Guilloteau et al., 2010; Górka et al., 2018).

\section{The role of gut bacteria in the maturation of the epithelium of the small intestine}

The influence of biologically active molecules present in colostrum and milk on the development of the intestinal epithelium of the small intestine has been thoroughly proven (Xu et al., 1992; Zabielski, 1998; Guilloteau et al., 2010). The effect of bacterial microflora on the intestine was also described (Marques et al., 2010; Patel et al., 2012,
Bäckhed et al., 2015). A well-researched example is the infection by enteropathogenic Escherichia coli (EPEC), which leads to reorganization within the tight junctions of the intestinal epithelium, especially in the early postnatal period (Muza-Moons et al., 2004). Vibrio cholerae produces a toxin (the zonula occludens toxin), which causes disintegration of tight junctions by acting on the zonula occludens protein, which increases the permeability of the intestinal barrier (Fasano et al., 1991). Currently, yet another factor is being discussed that may affect the development and maturation of the intestinal mucosa, since Galeano et al. (2014) have shown that bacterial lipopolysaccharide (LPS) induces in the intestines of young piglets functional disorders that cause reduced expression of the proteins that form the intestinal barrier. They observed reduced expression of Claudine 3 and 4 and zonula occludens- 1 proteins in piglets fed a diet containing LPS. These changes cause a disorder of selective transport, leading to the penetration of microorganisms and toxic compounds through the epithelium and to the cardiovascular system. The early time of weaning may also have had an impact on the epithelial disorder, since during this period foetal-type enterocytes were observed in the intestinal epithelium (Moon, 1972; Cera et al., 1988, Biernat, 2002), which implies its immaturity.

Reports of Pasternak et al. (2016) suggest that colonization of intestine by microorganisms is essential for the proper development of the small intestine in piglets just after birth. Colonization of the intestines by bacteria affects the regulation of the MAMDC4 expression. Furthermore, changes in the expression of MAMDC4 are affected by the kind of microbial species present in the gut.

\section{Conclusions}

As the intestine matures, the population of foetal enterocytes is replaced by mature-type enterocytes, which do not have the ability of forming transport or digestive vacuoles. The presence of the foetaltype enterocytes on the day of birth and their disappearance in due time are very important for the proper development of the intestine of the newborn, which is confirmed by their presence in the early postnatal period of development in a wide variety of mammalian species, including humans. The structure of foetal enterocytes shows large morphological similarity in many species of mammals. The modifications in the structure of foetal enterocytes observed in individuals with the 
intrauterine growth retardation (IUGR) syndrome may result in disorders of the development of the intestinal epithelium. It seems that further research required to understand the phenomenon of intestinal barrier should focus on explaining the processes associated with intracellular transport, based on localization and relocation (with age) of the transport proteins within the cellular connections. The structure and functioning of the cytoskeleton, whose participation in the transport through the cell is also important, requires a thorough analysis as well. The influence of the interstitial organ, newly described in the intestinal mucosa, on the paracellular transport, and the impact of bacteria on the functioning of the intestinal barrier should also be taken into account.

\section{Acknowledgments}

The work was partly supported by National Science Center (Poland), MINIATURA I (Grant No. 2017/01/X/NZ3/00744), the European Union from the European Regional Development Fund under the Operational Programme Development of Eastern Poland 2007-2013 (POPW.01.03.00-06003/09-00). A part of the study was conducted at the Veterinary Research Centre WULS (WCB) and the Center for Biomedical Research (CBB) supported by EFRR RPO WM 2007-2013.

\section{References}

Amdi C., Krogh U., Flummer C., Oksbjerg N., Hansen C.F., Theil P.K., 2013. Intrauterine growth restricted piglets defined by their head shape ingest insufficient amounts of colostrum. J. Anim. Sci. 91, 5605-5613, https://doi.org/10.2527/jas.2013-6824

Anderson C.L., Chaudhury C., Kim J., Bronson C.L., Wani M.A., Mohanty S., 2006. Perspective - FcRn transports album: relevance to immunology medicine. Trends Immunol. 27, 343-348, https://doi.org/10.1016/j.it.2006.05.004

Anderson J.M., Van Itallie C.M., 1995. Tight junctions and the molecular basis for regulation of paracellular permeability. Am. J. Physiol.-Gastroint. Liver Physiol. 269, G467-G475, https:// doi.org/10.1152/ajpgi.1995.269.4.G467

Bäckhed F., Roswall J., Peng Y. et al., 2015. Dynamics and stabilization of the human gut microbiome during the first year of life. Cell Host Microbe 17, 690-703, https://doi.org/10.1016/j. chom.2015.04.004

Baintner K. (Editor), 1986. Intestinal Absorption of Macromolecules and Immune Transmission from Mother to Young. CRC Press. Boca Raton, FL (USA)

Baintner K., 1994. Demonstration of acidity in intestinal vacuoles of the suckling rat and pig. J. Histochem. Cytochem. 42, 231-238, https://doi.org/10.1177/42.2.7507141

Baintner K., 2002. Vacuolation of the young. In: R. Zabielski, P.C. Gregory, B. Weström (Editors). Biology of the Intestine in Growing Animals. Elsevier. Amsterdam (The Netherlands), pp. 55-110, https://doi.org/10.1016/S1877-1823(09)70118-3
Baintner K., 2007. Transmission of antibodies from mother to young: evolutionary strategies in a proteolytic environment Vet. Immunol. Immunopathol. 117, 153-161, https://doi. org/10.1016/j.vetimm.2007.03.001

Bandrick M., Ariza-Nieto C., Baidoo S.K., Molitor T.W., 2014. Colostral antibody-mediated and cell-mediated immunity contributes to innate and antigen-specific immunity in piglets. Dev. Comp. Immunol. 43, 114-120, https://doi.org/10.1136/gut.37.3.353

Bardocz S., Grant G., Ewen S.W.B., Duguid T.J., Brown D.S., Englyst K., Pusztai A., 1995. Reversible effect of phytohaemagglutinin on the growth and metabolism of rat gastrointestinal tract. Gut 37, 353-360, https://doi.org/10.1016/ S1877-1823(09)70118-3

Bardocz S., Grant G., Pusztai A., Franklin M.F., Carvalho A.D.F.U., 1996. The effect of phytohaemagglutinin at different dietary concentration on the growth, body compositions and plasma insulin of the rat. Br. J. Nutr. 76, 613-626, https://doi. org/10.1079/BJN19960067

Benias P.C., Wells R.G., Sackey-Aboagye B. et al., 2018. Structure and distribution of an unrecognized interstitium in human tissues. Sci. Rep. 8, 4947, https://doi.org/10.1038/s41598-01823062-6

Biernat M., 2002. Factors regulating the growth and maturation of the structure and function of the small intestine of the piglets in the early postnatal period. PhD Thesis. The Kielanowski Institute of Animal Physiology and Nutrition, Polish Academy of Sciences. Jabłonna (Poland)

Biernat M., Zabielski R., Sysa P., Sosak-Swiderska B., Le HuërouLuron I., Guilloteau P., 1999. Small intestinal and pancreatic microstructures are modified by an intraduodenal CCK-A receptor antagonist administration in neonatal calves. Regul. Pept. 85, 77-85, https://doi.org/10.1016/S0167-0115(99)00079-8

Brandtzaeg P., Krajci P., 1995. The enterocyte and immunoglobulin transport. In: S. Auricchio, R. Troncone, A. Ferguson (Editors). Mucosal Immunity and the Gut Epithelium: Interactions in Health and Disease. Series: Dynamic Nutrition Research, Volume 4. S. Karger AG. New York, NY (USA)

Burton K.A., Smith M.W., 1977. Endocytosis and immunoglobulin transport across the small intestine of the new-born pig. J. Physiol. 270, 473-488, https://doi.org/10.1113/jphysiol.1977.sp011963

Cera K.R., Mahan D.C., Cross R.F., Reinhart G.A., Whitmoyer R.E., 1988. Effect of age, weaning and postweaning diet on small intestinal growth and jejunal morphology in young swine. J. Anim. Sci. 66, 547-584, https://doi.org/10.2527/ jas1988.662574x

Chastant-Maillard S., Freyburger L., Marcheteau E., Thoumire S., Ravier J.F., Reynaud K., 2012. Timing of the intestinal barrier closure in puppies. Reprod. Domest. Anim. 47, 190-193, https://doi.org/10.1111/rda.12008

Childs A.C., Mehta D.J., Gerner E.W., 2003. Polyamine-dependent gene expression. Cell. Mol. Life Sci. 60, 1394-1406, https:// doi.org/10.1007/s00018-003-2332-4

Clarke R.M., Hardy R.N., 1971. Histological changes in the small intestine of the young pig and their relation to macromolecular uptake. J. Anat. 108, 63-77

Danielsen E.M., Hansen G.H., 2016. Small molecule pinocytosis and clathrin-dependent endocytosis at the intestinal brush border: Two separate pathways into the enterocyte. Biochim. Biophys. Acta-Biomembr. 1858, 233-243, https://doi. org/10.1016/j.bbamem.2015.11.022

Dekaney C.M., Bazer F.W., Jaeger L.A., 1997. Mucosal morphogenesis and cytodifferentiation in fetal porcine small intestine. Anat. Rec. 249, 517-523, https://doi.org/10.1002/(SICI)10970185(199712)249:4<517::AID-AR12>3.0.CO;2-R 
Denno D.M., VanBuskirk K., Nelson Z.C., Musser C.A., Hay Burgess D.C., Tarr P.I., 2014. Use of the lactulose to mannitol ratio to evaluate childhood environmental enteric dysfunction: a systematic review. Clin. Infect. Dis. 59, Suppl. 4, S213-S219, https://doi.org/10.1093/cid/ciu541

Dörfel M., Huber O., 2012. Modulation of tight junction structure and function by kinases and phosphatases targeting occludin. J. Biomed. Biotechnol. 2012, 807356, https://doi. org/10.1155/2012/807356

Ekström G.M., Weström B.R., Telemo E., Karlsson B.W., 1988. The uptake of fluorescein-conjugated dextran 70,000 by the small intestinal epithelium of the young rat and pig in relation to macromolecular transmission into the blood. J. Dev. Physiol. 10, 227-233

Elbrønd V.S., Weström B.R., 2007. The early postnatal pattern of vesicle formation in different regions of the porcine small intestine. Livest. Sci. 108, 142-145, https://doi.org/10.1016/j. livsci.2007.01.028

Fasano A., Baudry B., Pumplin D.W., Wasserman S.S., Tall B.D., Ketley J.M., Kaper J.B., 1991. Vibrio cholerae produces a second enterotoxin, which affects intestinal tight junctions. Proc. Natl. Acad. Sci. U. S. A. 88, 5242-5246, https://doi.org/10.1073/ pnas.88.12.5242

Ferenc K., Pilżys T., Skrzypek T. et al., 2017. Structure and function of enterocyte in intrauterine growth retarded pig neonates. Dis. Markers 2017, 5238134, https://doi. org/10.1155/2017/5238134

Fujita M., Baba R., Shimamoto M., Sakuma Y., Fujimoto S., 2007. Molecular morphology of the digestive tract; macromolecules and food allergens are transferred intact across the intestinal absorptive cells during the neonatal-suckling period. Med. Mol. Morphol. 40, 1-7, https://doi.org/10.1007/s00795-006-0346-3

Fujita M., Reinhart F., Neutra M., 1990. Convergence of apical and basolateral endocytic pathways at the apical late endosomes in absorptive cells of suckling rat ileum in vivo. J. Cell Sci. 97, 385-394

Galeano J.A.C., Herrera A.L., Suescún J.P., 2014. E. coli lipopolysaccharide decreases the expression of proteins of tight junctions in the jejunum of weaning piglets. Rev. Fac. Nac. Agron. 67, 7301-7310, https://doi.org/10.15446/rfnam.v67n2.44172

Godlewski M.M., Słupecka M., Woliński J., Skrzypek T., Skrzypek H., Motyl T., Zabielski R., 2005. Into the unknown - the death pathways in the neonatal gut epithelium. J. Physiol. Pharmacol. 56, Suppl. 3, 7-24

Górka P., Kowalski Z.M., Zabielski R., Guilloteau P., 2018. Use of butyrate to promote gastrointestinal tract development in calves. J. Dairy. Sci. 101, 4785-4800, https://doi.org/10.3168/ jds.2017-14086

Grognet J.-F., Duvaux-Ponter Ch., 1998. Acquisition of passive immunity in domestic ungulates. J. Anim. Feed Sci. 7, Suppl. 1 93-114, https://doi.org/10.22358/jafs/69958/1998

Guilloteau P., Zabielski R., Hammon H.M., Metges C.C., 2010. Nutritional programming of gastrointestinal tract development. Is the pig a good model for man? Nutr. Res. Rev. 23, 4-22, https://doi.org/10.1017/S0954422410000077

Guyton A.C., Hall J.E., 1996. Digestion and absorption in the gastrointestinal tract. In: Textbook of Medical Physiology. $9^{\text {th }}$ Edition W.B. Saunders Co. Philadelphia, PA (USA)

Heird W.C., Schwarz S.M., Hansen I.H., 1984. Colostrum-induced enteric mucosal growth in beagle puppies. Pediatr. Res. 18 , 512-515, https://doi.org/10.1203/00006450-198406000-00005

Hollander D., 1992. The intestinal permeability barrier. A hypothesis as to its regulation and involvement in Crohn's Disease. Scand. J. Gastroenterol. 27, 721-726, https://doi. org/10.3109/00365529209011172
Jensen A.R., Elnif J., Burrin D.G., Sangild P.T., 2001. Development of intestinal immunoglobulin absorption and enzyme activities in neonatal pigs is diet dependent. J. Nutr. 131, 3259-3265, https://doi.org/10.1093/jn/131.12.3259

Kacskovics I., 2004. Fc receptors in livestock species. Vet. Immunol. Immunopathol. 102, 351-362, https://doi.org/10.1016/j. vetimm.2004.06.008

Kaouas M., Deloyer P., Gouders I., Peulen O., Dandrifosse G., 1997. Role of interleukin-1 $\beta$, interleukin- 6 and TNF- $\alpha$ in intestinal maturation induced by dietary spermine in rats. Endocrine 6, 187-194, https://doi.org/10.1007/BF02738963

Kelly D., Begbie R., King T.P., 1992. Postnatal intestinal development. In: M.A. Varley, P.E.V. Williams, T.L.J. Lawrence (Editors). Neonatal Survival and Growth. BSAP. Penicuik (UK), pp. 63-79

Kotunia A., Woliński J., Laubitz D., Jurkowska M., Romé V., Guilloteau P., Zabielski R., 2004. Effect of sodium butyrate on the small intestine development in neonatal piglets fed [correction of feed] by artificial sow. J. Physiol. Pharmacol. 55, Suppl. 2, $59-68$

König J., Wells J., Cani P.D., García-Ródenas C.L., MacDonald T., Mercenier A., Whyte J., Troost F., Brummer R.-J., 2016. Human intestinal barrier function in health and disease. Clin. Transl. Gastroenterol. 7, e196, https://doi.org/10.1038/ctg.2016.54

Lecce J.G., 1973. Effect of dietary regimen on cessation of uptake of macromolecules by piglet intestinal epithelium (closure) and transport to the blood. J. Nutr. 103, 751-756, https://doi. org/10.1093/jn/103.5.751

Lecce J.G., Broughton C.W., 1973. Cessation of uptake of macromolecules by neonatal guinea pig, hamster and rabbit intestinal epithelium (closure) and transport into blood. J. Nutr. 103, 744-750, https://doi.org/10.1093/jn/103.5.744

Lecce J.G., Morgan D.O., 1962. Effect of dietary regimen on cessation of intestinal absorption of large molecules (closure) in the neonatal pig and lamb. J. Nutr. 78, 263-268, https://doi. org/10.1093/jn/78.3.263

Marques T.M., Wall R., Ross R.P., Fitzgerald G.F., Ryan C.A., Stanton C., 2010. Programming infant gut microbiota: influence of dietary and environmental factors. Curr. Opin. Biotechnol. 21 149-156, https://doi.org/10.1016/i.copbio.2010.03.020

McCarter S.D., Johnson D.L., Kitt K.N., Donohue C., Adams A., Wilson J.M., 2010. Regulation of tight junction assembly and epithelial polarity by a resident protein of apical endosomes. Traffic 11, 856-866, https://doi.org/10.1111/j.1600-0854.2010.01052.x

Michanek P., Ventrop M., Weström B., 1989. Intestinal transmission of colostral antibodies in newborn dairy calves: Initiation of closure by feeding colostrum. Swed. J. Agric. Res. 19, 125-134

Mickiewicz M., Zabielski R., Grenier B., Le Normand L., Savary G., Holst J.J., Oswald I.P., Metges C.C., Guilloteau P., 2012. Structural and functional development of small intestine in intrauterine growth retarded porcine offspring born to gilts fed diets with differing protein ratios throughout pregnancy. J. Physiol. Pharmacol. 63, 225-239

Moon H.W., 1972. Vacuolated villous epithelium of the small intestine of young pigs. Vet. Pathol. 9, 3-12, https://doi. org/10.1177/030098587200900102

Moretti D.B., Nordi W.M., Lima A.L., Pauletti P., Machado-Neto R., 2013. Enterocyte lgG uptake in the small intestine of goat kids during the period of passive immunity acquisition. Small Ruminant Res. 114, 182-187, https://doi.org/10.1016/j.smallrumres.2013.05.012

Muza-Moons M.M., Schneeberger E.E., Hecht G.A., 2004. Enteropathogenic Escherichia coli infection leads to appearance of aberrant tight junctions strands in the lateral membrane of intestinal epithelial cells. Cell. Microbiol. 6, 783-793, https:// doi.org/10.1111/j.1462-5822.2004.00404.x 
Nechvatalova K., Kudlackova H., Leva L., Babickova K., Faldyna M., 2011. Transfer of humoral and cell-mediated immunity via colostrum in pigs. Vet. Immunol. Immunopathol. 142, 95-100, https://doi.org/10.1016/j.vetimm.2011.03.022

Neu J., Shenoy V., Chakrabarti R., 1996. Glutamine nutrition and metabolism: Where do we go from here? FASEB J. 10, 829-837, https://doi.org/10.1096/fasebj.10.8.8666159

Pasternak A.J., Hamonic G.M., Van Kessel A., Wilson H.L., 2016. Postnatal regulation of MAMDC4 in the porcine intestinal epithelium is influenced by bacterial colonization. Physiol. Rep. 4, e13018, https://doi.org/10.14814/phy2.13018

Pasternak J.A., Kent-Dennis C., Van Kessel A.G., Wilson H.L., 2015. Claudin-4 undergoes age-dependent change in cellular localization on pig jejunal villous epithelial cells, independent of bacterial colonization. Mediat. Inflamm. 2015, e263629, https://doi.org/10.1155/2015/263629

Patel R.M., Myers L.S., Kurundkar A.R., Maheshwari A., Nusrat A., Lin P.W., 2012. Probiotic bacteria induce maturation of intestinal claudin 3 expression and barrier function. Am. J. Pathol. 180, 626-635, https://doi.org/10.1016/j.ajpath.2011.10.025

Pierzynowski S.G., Sjodin A., 1998. Perspectives of glutamine and its derivatives as feed additives for farm animals. J. Anim Feed Sci. 7, Suppl. 1, 79-91, https://doi.org/10.22358/ jafs/69957/1998

Pluske J., Hampson D., Williams I.H., 1997. Factors influencing the structure and function of the small intestine in weaned pigs: a review. Livest. Prod. Sci. 51, 215-236, https://doi. org/10.1016/S0301-6226(97)00057-2

Rådberg K., Biernat M., Linderoth A., Zabielski R., Pierzynowski S.G., Weström B.R., 2001. Enternal exposure to crude red kidney bean lectin induces maturation of the gut in suckling pigs. J. Anim. Sci. 79, 2669-2678, https://doi. org/10.2527/2001.79102669x

Salmon H., 2012. Colostral and lactogenic maternal immunity: Humoral and cellular factors of induction and transmission to the neonate. In: B. Rekik (Editor). Milk Production. Food Science and Technology Series. Nova Science Publishers. Hauppauge, NY (USA), pp. 37-73

Salmon H., Berri M., Gerdts V., Meurens F., 2009. Humoral and cellular factors of maternal immunity in swine. Dev. Comp. Immunol. 33, 384-393, https://doi.org/10.1016/j.dci.2008.07.007

Sangild P.T., 2001. Transitions in the life of the gut at birth. In: J.E. Lindberg, B. Ogle (Editors). Digestive Physiology of Pigs. Proceedings of the $8^{\text {th }}$ Symposium, Swedish University of $\mathrm{Ag}$ ricultural Sciences, Uppsala, Sweden, 20-22 June 2000. $\mathrm{CABI}$ Publishing. Wallingford (UK), pp. 3-16, https://doi. org/10.1079/9780851995175.0003

Sangild P.T., 2003. Uptake of colostral immunoglobulins by the compromised newborn farm animal. Acta Vet. Scand. 44, Suppl. 1 , S105, https://doi.org/10.1186/1751-0147-44-S1-S105

Sangild P.T., Xu R.J., Trahair J.F., 2002. Maturation of intestinal function: the role of cortisol and birth. In: R. Zabielski, P.C. Gregory, B.R. Weström (Editors). Biology of the Small Intestine in Growing Animals. Elsevier. Amsterdam (The Netherlands), pp. 111-144, https://doi.org/10.1016/S1877-1823(09)70119-5

Seiler N., Raul F., 2005. Polyamines and apoptosis. J. Cell. Mol. Med. 9 , 632-642, https://doi.org/10.1111/j.1582-4934.2005.tb00493.x

Simister N.E., 2003. Placental transport of immunoglobulin G. Vaccine 21, 3365-3369, https://doi.org/10.1016/S0264410X(03)00334-7

Skrzypek T., Valverde Piedra J.L., Skrzypek H., Kazimierczak W., Biernat M., Zabielski R., 2007a. Gradual disappearance of vacuolated enterocytes in the small intestine of neonatal piglets. J. Physiol. Pharmacol. 58, Suppl. 3, 87-95
Skrzypek T., Valvedre Piedra J.L., Skrzypek H., Kazimierczak W., Szymańczyk S., Pawłowska M., Zabielski R., 2007b. Intestinal villi structure during the development of pig and wild boar crossbreed neonates. Livest. Sci. 109, 38-41, https://doi. org/10.1016/j.livsci.2007.01.040

Skrzypek T., Valverde Piedra J.L., Skrzypek H., Woliński J., KazimierczakW., Szymańczyk S., Pawłowska M., Zabielski R., 2005. Light and scanning electron microscopy evaluation of the postnatal small intestinal mucosa development in pigs. J. Physiol. Pharmacol. 56, Suppl. 3, 71-87

Skrzypek T., Kazimierczak W., Skrzypek H., Valverde Piedra J.L., Godlewski M.M., Zabielski R., 2018. Mechanisms involved in the development of the small intestine mucosal layer in postnatal piglets. J. Physiol. Pharmacol. 69, 127-138, https:// doi.org/10.26402/jpp.2018.1.14

Svendsen L.S., Weström B.R., Svendsen J., Ohlsson B.G., Ekman R., Karlsson B.W., 1986. Insulin involvement in intestinal macromolecular transmission and closure in neonatal pigs. J. Pediatr. Gastroenterol. Nutr. 5, 299-304, https://doi. org/10.1097/00005176-198605020-00024

Teichberg S., Wapnir R.A., Moyse J., Lifshitz F., 1992. Development of the neonatal rat small intestinal barrier to nonspecific macromolecular absorption. II. Role of dietary corticosterone. Pediatr. Res. 32, 50-57, https://doi.org/10.1203/00006450199207000-00010

Trahair J.F., 1993. Review: Is fetal enteral nutrition important for normal gastrointestinal growth? A discussion. J. Parenter. Enter. Nutr. 17, 82-85, https://doi.org/10.1177/014860719301700182

Trahair J.F., Sangild P.T., 1997. Systemic and luminal influences on the perinatal development of the gut. Equine Vet. J. 29, Suppl. 24, 40-50, https://doi.org/10.1111/j.2042-3306.1997. tb05077.x

Travis S., Menzies I., 1992. Intestinal permeability: functional assessment and significance. Clin. Sci. 82, 471-488, https:// doi.org/10.1042/cs0820471

Tyler H., Ramsey H., 1993. Effect of insulin-induced hypoglycemia on cessation of macromolecular transport in the neonatal calf. J. Dairy Sci. 76, 2736-2741, https://doi.org/10.3168/jds.S00220302(93) $77610-9$

Vukavić T., 1984. Timing of the gut closure. J. Pediatr. Gastroenterol. Nutr. 3, 700-703, https://doi.org/10.1097/00005176198411000-00011

Wang W., Degroote J., Van Ginneken C., Van Poucke M., Vergauwen H., Dam T.M.T., Vanrompay D., Peelman L.J., De Smet S., Michiels J., 2016. Intrauterine growth restriction in neonatal piglets affects small intestinal mucosal permeability and mRNA expression of redox-sensitive genes. FASEB $\mathrm{J}$. 30, 863-873, https://doi.org/10.1096/fj.15-274779

Wang X., Lin G., Liu C., Feng. C., Zhou H., Wang T., Li D., Wu G., Wang J., 2014. Temporal proteomic analysis reveals defects in small-intestinal development of porcine fetuses with intrauterine growth restriction. J. Nutr. Biochem. 25, 785-795, https://doi.org/10.1016/j.jnutbio.2014.03.008

Weaver L.T., Walker W.A., 1989. Uptake of macromolecules in the neonate. In: E. Lebenthal, (Editor). Human Gastrointestinal Development. Raven Press, New York (USA), pp. 731-748

Weström B.R., Svendsen J., Ohlsson B.G., Tagesson C., Karlsson B.W., 1984. Intestinal transmission of macromolecules (BSA and FITC-labelled dextran) in the neonatal pig: influence of age of piglet and molecular weight of markers. Biol. Neonate. 46, 20-26, https://doi.org/10.1159/000242028

Widdowson E.M., Colombo V.E., Artavanis C.A., 1976. Changes in the organs of pigs in response to feeding for the first $24 \mathrm{~h}$ after birth. II. The digestive tract. Biol. Neonate. 28, 272-281, https://doi.org/10.1159/000240828 
Wilson J.M., Whitney J.A., Neutra M.R., 1987. Identification of an endosomal antigen specific to absorptive cells of suckling rat ileum. J. Cell Biol. 105, 691-703, https://doi.org/10.1083/ jcb.105.2.691

Xu R.J., Mellor D.J., Tungthanathanich P., Birtles M.J., Reynolds G.W., Simpson H.V., 1992. Growth and morphological changes in the small intestine in piglets during the first three days after birth. J. Dev. Physiol. 18, 161-172

Yamashiro Y., Sato M., Shimizu T., Oguchi S., Maruyama K., Kitamura S., 1989. Possible biological growth factors in breast milk and postnatal development of the gastrointestinal tract. Pediatr. Int. 31, 417-423, https://doi.org/10.1111/j.1442200X.1989.tb01327.x
Zabielski R., 1998. Regulatory peptides in milk, food and in the gastrointestinal lumen of young animals and children. J. Anim. Feed Sci. 7, 65-78, https://doi.org/10.22358/jafs/69956/1998

Zabielski R., 2007. Hormonal and neural regulation of intestinal function in pigs. Livest. Sci. 108, 32-40, https://doi. org/10.1016/j.livsci.2007.01.022 